\title{
ANÁLISE DAS INTELIGÊNCIAS MÚLTIPLAS DOS GRADUANDOS DO CURSO DE ADMINISTRAÇÃO DA UNIVERSIDADE REGIONAL DE BLUMENAU
}

\section{1- Marcos Polli \\ Universidade Regional de Blumenau - FURB m-polli@bol.com.br}

\author{
3- Maria José C. de S. Domingues \\ Universidade Regional de Blumenau - FURB \\ mariadomingues@furb.br
}

\author{
2- Jaison Ademir Sevegnani \\ Universidade Regional de Blumenau - FURB \\ jaison.sevegnani@terra.com.br \\ 4- Nelson Hein \\ Universidade Regional de Blumenau - FURB \\ hein@furb.br
}

\section{RESUMO}

A análise das inteligências múltiplas desenvolvida por Gardner é importante, pois possibilita conhecer os estilos de aprendizagem tanto aos docentes quanto aos discentes. O objetivo deste estudo foi apresentar os resultados de uma pesquisa realizada na Universidade Regional de Blumenau (FURB) com os discentes do curso de graduação em Administração utilizando o Inventário das Inteligências Múltiplas (IIM) criado por Armstrong (2001), fazendo ainda considerações para o desenvolvimento de estratégias de ensino por parte dos docentes por meio do conceito das 8 inteligências múltiplas propostas por Gardner. A metodologia utilizada foi à pesquisa descritiva, com método do tipo levantamento com dados quantitativos. Foram coletados dados com 305 discentes do curso de graduação em Administração, divididos com ênfase no curso Comércio Exterior e no curso Gestão Empresarial. A análise foi realizada por meio da teoria de análise de regressão com auxílio do software LHStat. As inteligências que mais se destacaram foram a lógicomatemática, a inteligência interpessoal e a inteligência corporal cinestésica, as inteligências que apresentaram decréscimo foram às inteligências, naturalista, musical, lingüística, espacial e intrapessoal, com isto sugere-se novas estratégias e métodos de ensino mais adequados aos docentes, com objetivo de melhorar a didática na sala de aula.

Palavras-Chave

Inteligências Múltiplas. Metodologia de Ensino. Estratégia de Ensino.

\section{ABSTRACT}

The analysis of the multiple intelligences developed by Gardner is important, because it makes possible to know the learning styles so much to the teachers as for the students. The objective of this study was to present the results of a research accomplished in the Regional University of Blumenau (FURB) with the students of the degree course in Administration using the Inventory of the Multiple Intelligences (IIM) created by Armstrong (2001), still making considerations for the development of teaching strategies on the part of the teachers through the concept of the 8 multiple intelligences proposed by Gardner. The used methodology went to the descriptive research, with method of the type rising with quantitative data. Data were collected with 305 students of the degree course in Administration, divided with emphasis in the course External Trade and in the course Business Administration. The analysis was accomplished through the theory of regression analysis with aid of the software LHStat. The intelligences that more it highlighted were the logical-mathematics, the interpersonal intelligence and the kinesthetic intelligence, the intelligences that presented decrease went to the intelligences, naturalistic, musical, linguistics, space and intrapersonal intelligence, with this suggests herself new strategies and more appropriate teaching methods to the teachers, with objective of improving the didacticism in the classroom.

\section{Keywords}

Multiple intelligences. Methodology of Teaching.Teaching strategy. 


\section{Introdução}

A origem do conceito sobre inteligências múltiplas surge dos esforços de Howard Gardner e sua equipe para aperfeiçoar os estudos sobre o desenvolvimento das capacidades cognitivas normais assim como avaliar tais capacidades em crianças que manifestavam algum tipo de patologia (GARNER, 2003).

A delimitação simples da conceituação de inteligência é um conceito que se mostrou em construção nas últimas décadas, Gardner (1994) ao explanar sobre as Inteligências Múltiplas (IM) demonstrou uma visão histórica sobre a inteligência e apontou para uma capacidade de resolver problemas e quando adequado para criar produtos que respondam tais situações, dentro de um processo de desenvolvimento do conhecimento.

Gardner (2003) reforça a importância da discussão e evolução das inteligências múltiplas de forma particular afirmando que, desejaria ter dedicado mais tempo as ramificações de tais inteligências e mesmo passadas duas décadas da publicação sobre IM os defensores da inteligência geral atualmente necessitam defender sua posição, algo impensável há duas décadas.

De maneira abrangente a inteligência é considerada como um produto ou conjunto de habilidades que permite ao sujeito resolver situações ou criar determinados itens que possuam valores dentro de um determinado ambiente (GARDNER, 1994; ANTUNES, 1998).

Ainda há de ressaltar-se que estas utilizações demandam um profundo conhecimento do ambiente onde o professor está inserido e do preparo para o manuseio de instrumentos que fogem aos "padrões" locais, contudo, serão vitais para a absorção pelas inteligências manifestantes na sala de aula. Outro ponto relevante é saber que a utilização das IM não se limita única e exclusivamente no ambiente acadêmico e as paredes da sala de aula. (ARMSTRONG, 2001).

Destaca-se a importância do estudo de Howard Gardner e de sua equipe na Universidade de Harvard que no início da década de 80 instituiu a Teorias das Inteligências Múltiplas, onde a inteligência era vista sob um prisma de 7 (sete) lados: lingüística, lógico-matemática, espacial, corporal-cinestésica, musical, interpessoal, intrapessoal e recentemente a inteligência naturalista, formando um constructo de 8 (oito) inteligências.

O presente artigo traz como objetivo apresentar os resultados de uma pesquisa realizada recentemente no campus 1 da Universidade Regional de Blumenau (FURB) com os discentes do curso de graduação em Administração utilizando o Inventário das Inteligências Múltiplas (IIM) criado por Armstrong (2001) e já utilizado em um estudo semelhante por Walter et al, (2006). Objetiva-se ainda propor estratégias de ensino que, utilizandose do conceito de inteligências múltiplas, permitam aos docentes adotar ferramentas de ensino visando equilibrar nos alunos as oito inteligências propostas por Gardner.

\section{Inteligências Múltiplas}

As inteligências foram classificadas de forma múltipla, contendo: inteligência matemática, inteligência lingüística, inteligência intrapessoal, inteligência interpessoal, inteligência corporalcinestésica, inteligência musical, inteligência espacial e mais recentemente foi acrescentada a inteligência naturalista (ARMSTRONG, 2001).

Complementar ao conceito observa-se que as inteligências múltiplas estão ligadas a diversos fatores: físicos, neurológicos ou sociais como a cultura onde se insere o indivíduo (FLECK, 2008)

A inteligência lingüística responde pela produção da linguagem é relacionada ao processo de geração da linguagem tal como: declamação de poemas, contarem estórias, gramática, raciocínio abstrato, pensamento simbólico, jogos de palavras, entre outros. (PASSARELLI, 1995; ARMSTRONG, 2001).

Existe uma contextualização sobre a origem da inteligência lingüística amplamente aceita independente da sua aplicabilidade futura, que apregoa a origem da capacidade lingüística que envolve processos especiais de aquisição que são paralelos aos requeridos em outras inteligências (GARDNER, 1994).

No caso da inteligência lingüística observar-se ainda que ela normalmente aponta um perfil com capacidade de convencer alguém sobre um fato, senso de humor, memória e lembrança, capacidade de explicar, entre outros. Um estudo recente realizado na China utiliza os conceitos das inteligências múltiplas visando aprimorar o ensino da língua inglês e demonstra a potencialidade ao possibilitar um ensino eficaz para cada estudante (PASSARELLI, 1995; KONG, 2009).

O desenvolvimento da inteligência lógicomatemática reside para Gardner (1994) em grande parte na obra de Piaget, assim o desenvolvimento de tal inteligência inicia-se nas primeiras ações do bebê desenvolvendo-se gradativamente durante a 
primeira ou as duas primeiras décadas da sua vida. A inteligência lógico-matemática pode ser definida como uma capacidade de utilização de raciocínio efetivo para a formulação de cálculos e relacionamentos lógicos; sua origem remonta a observação do mundo material, ou seja, um confronto com o mundo dos objetos.

Esta inteligência contempla categorização, classificação, cálculo e teste de hipóteses e associa-se a linhas de pensamento indutivo e dedutivo também; além de apontar para utilização no discernimento de soluções e conexões (GARDNER, 1994; PASSARELLI, 1995; ARMSTRONG, 2001).

A origem da inteligência espacial e seu desenvolvimento ainda não estão bem esclarecidos, embora já existam muitos estudos com adultos, as pesquisas envolvendo crianças ainda não são conclusivas, ainda há de acrescer-se que testar esta inteligência é muito mais complexo do que as inteligências anteriores, a única ressalva neste sentido reside nos estudos feitos por Piaget, contudo não apontam para uma unanimidade (GARDNER, 1994).

A inteligência espacial consiste na capacidade de percepção do ambiente e executar alterações e criações em um determinado ambiente mesmo ausente de estímulos físicos suficientes, tal inteligência envolve sensibilidade a cor, formas, espaço entre outras (GARDNER, 1994; ARMSTRONG, 2001).

Passarelli (1995) complementa ao escrever que o perfil desta inteligência aponta para características como: formação de imagens mentais, manipulação de imagens, representação gráfica, reconhecimento de relações de objetos no espaço, etc.

A forma como a cultura ocidental separou em hemisférios distintos; corpo e mente pode gerar certo espanto ao apresentar-se a inteligência corporal-cinestésica, esta pode ser definida como a utilização da sabedoria do corpo, o uso do córtex cerebral que controla a movimentação corporal (GARDNER, 1994; PASSARELLI, 1995). Esta inteligência pode ser encontrada normalmente em atores, dançarinos, coreógrafos, atletas, artesãos e artistas plásticos. Passarelli (1995) coloca que se tornam características marcantes nesta inteligência: funções corporais desenvolvidas, habilidades miméticas, controle dos movimentos préprogramados, controle dos movimentos voluntários.

A inteligência musical é colocada por Antunes (2003) como a capacidade de combinar e compor sons musicais, os seqüenciado com lógica e ritmo, estruturando-os e criando harmonias e melodias além de deter um entendimento "geral" do contexto musical (ARMSTRONG, 2001). Esta inteligência sinaliza algumas habilidades inatas como: reconhecimento da estrutura musical, sensibilidade para sons, criação de melodias e ritmos, habilidade para tocar instrumentos (PASSARELLI, 1995).

A inteligência interpessoal é uma das inteligências que se aplica e que possui grande influência e importância em todas as sociedades globais (GARDNER,1994).Caracteriza-se como a síntese do relacionamento eficiente com os outros e na percepção sobre aspectos pessoais de outros indivíduos. Isso explica a facilidade de grandes comunicadores e líderes históricos, além de ajudar na compreensão da empatia demonstrada por algumas pessoas (WALTER et al, 2006).

A inteligência intrapessoal inclui a detenção de uma imagem exato de si próprio, consciência dos estados de humor, intenções, capacidade de autodisciplina, auto-atendimento entre outros (ARMSTRONG, 2001).

A inteligência intrapessoal permite ao indivíduo experenciar a unidade e o todo, intuições sobre o futuro e sonhar e buscar a realização de determinados objetivos. O perfil delimitado nesta inteligência converge para a preocupação, a concentração total da mente, senso de autoconhecimento até a capacidade de abstração e de raciocínio e a administração de sentimentos, projetos e limitações. (PASSARELLI,1995; WALTER et al, 2008).

A inteligência naturalista foi à última a ser colocada por Gardner, faz menção à capacidade de reconhecimento e classificação das espécies no meio ambiente do indivíduo. A aplicação desta inteligência também é valida em indivíduos com nascimento e desenvolvimento urbano, os quais realizam sua distinção entre seres inanimados como: carros, motos, placas e seres vivos (animais, insetos e demais seres humanos).

Existem algumas ponderações a respeito das IM, Gardner (1994) afirma que esta teoria pode ser anulada caso as atividades humanas mais significativas não possam ser explicadas ou possam ser mais bem explicadas em termos de teorias concorrentes, então a teoria das IM será devidamente rejeitada.

Cabe mencionar a possibilidade do acréscimo de uma nona inteligência, a inteligência existencial, define-se como uma preocupação extremamente básica com as questões da vida, sugere que 
"qualquer representação do espectro de inteligências humanas deveria incluir a busca tão antiga da humanidade das respostas básicas da vida: 'Quem somos nós? ', 'Qual é o sentido disso tudo? ' 'Por que existe o mal? ' entre outras" (ARMSTRONG, 2001, p.163).

Outros estudos ainda corroboram com Gardner, os questionamentos em torno das inteligências múltiplas na verdade estão condicionados muito além da discussão sobre as inteligências apresentadas por Gardner ou a discussão sobre a inclusão de novas inteligências (ARMOSTRONG 2001), transcende estas barreiras e é colocada na resolução de transtornos rotineiros como a forma de operacionalizar as IM em sala de aula; utilização de mecanismos de ensino específicos para as individualidades de publico encontradas no ambiente acadêmico; ou talvez até mais complexa tarefa, identificar como é composto seu público e qual a inteligência predominante naquele ambiente, a fim de criar uma comunicação que alcance o desafio de transmitir e instigar o conhecimento. A própria teoria acaba estimulando os professores a ativar e manter os comportamentos revelados de cada inteligência, respeitadas as individualidades (WALTER et al, 2006; ARMSTRONG, 2001; SILVA, 2007).

Na visão de Mokhtar; Majid; Foo (2007) sobre a teoria de Gardner, afirma-se que as inteligências múltiplas estão presentes no indivíduo, embora existam algumas inteligências quase inexistentes, outras inteligências desenvolvem-se a ponto de individualmente atenderem ao propósito colocado por Antunes (1998) como função principal de uma inteligência, ou seja, a resolução de problemas ou criação de produtos com um valor determinado em uma cultura ou comunidade específica.

Ainda, dentre os diversos materiais sobre estilos de aprendizagem Nielsen (2008) corrobora reforçando que estudos sobre o processo de aprendizagem e a utilização de IM fazem parte deste processo de discussão, tais estudos encontram-se na prática da educação de adultos e na sua contextualização.

Cabe ainda a ressalva de recentes estudos de Gardner para o que seria a nona inteligência, a inteligência existencial; sendo esta uma capacidade para contemplar fenômenos sensoriais ou perguntas para além de dados, próxima da cosmologia (MORAN; KORNHABER; GARDNER, 2006).

\section{Método de Pesquisa}

Os procedimentos metodológicos utilizados no estudo para a consecução do objeto proposto foram à pesquisa descritiva com método do tipo levantamento, com dados quantitativos, caracterizando uma survey.

Coletaram-se dados secundários no intuito de averiguar os estudos sobre inteligências multiplas através de pesquisa bibliográfica. Os dados primários foram coletados por meio do Inventário das Inteligências Múltiplas (IIM) instrumento criado por Armstrong (2001), formando um constructo de múltiplas escolhas e que forma aplicada pelos pesquisadores.

A pesquisa desenvolveu-se em curso com mais de 30 anos de existência, sendo atualmente oferecido em dois períodos: matutino (ênfase em Gestão Empresarial) e noturno (Gestão Empresarial e Comércio Exterior).

O estudo foi realizado entre os meses de Maio e Junho de 2008 no campus 1 da Universidade Regional de Blumenau (FURB). A população envolvendo a graduação em Administração contava com 1453 acadêmicos e para efeito da pesquisa utilizou-se uma amostra de alunos deste curso, desde o primeiro ano até o último ano da graduação, foram aplicados 305 questionários representando uma margem de erro de $5 \%$ na amostragem. A coleta de dados deu-se com a aplicação da equipe de pesquisa nas salas de aula da graduação e a entrega dos IIMs aos alunos presentes no instante de aplicação da pesquisa.

O instrumento de auxílio na análise dos dados coletados foi o Software LHStat e a função utilizada para a análise foi o método de análise de regressão e correlação. Para efeito de cálculo todas as inteligências foram analisadas sob a face de variáveis dependentes ao passo que a análise considerou o ano como a variável independente, sendo assim utiliza-se duas variáveis métricas visando examinar a associação entre as duas, neste artigo, correlacionando ano e inteligências (HAIR, 2005)

Foram coletados dados com 305 alunos, sendo $172(56,39 \%)$ do sexo feminino e $133(43,61 \%)$ do sexo masculino. Estes discentes estavam divididos por ênfase da seguinte forma: $99 \quad(32,46 \%)$ discentes de Comércio Exterior e 206 (67,54\%) discentes de Gestão Empresarial. A divisão por período representa-se da seguinte forma: 44 $(14,43 \%)$ discentes no período matutino e 261 $(85,57 \%)$ discentes no período noturno. 
Os valores obtidos para referência de uma inteligência no início de cada curso foi o fornecido pelo LHStat como constante da equação. Já os valores médios de crescimento ou decréscimo para uma referida inteligência também fora retirada da equação de regressão fornecida pelo software.

Os coeficientes de regressão estimados são usados para calcular os valores previstos para cada observação e para expressar a variação esperada na variável dependente para cada variação unitária na variável independente, sendo possível analisar o impacto de cada variável independente na previsão da dependente. (HAIR et al,2005).

\section{Resultados da Pesquisa}

Observa-se no quadro 1 que as inteligências de modo geral, demonstraram acréscimo ou decréscimo ao longo dos cinco anos da graduação em administração.

Quadro 1 - Resultado da pesquisa Inteligências Múltiplas

\begin{tabular}{|c|c|c|}
\hline Inteligência & Equação & Variação \\
\hline Lingüística & $4,13784-0,0482585$ * ANO & $(4,83 \%)$ \\
\hline Lógico-matemática & $3,86262+0,184057$ * ANO & $18,41 \%$ \\
\hline Espacial & $3,98054-0,0384001$ * ANO & $(3,84 \%)$ \\
\hline Corporal-cinestésica & $4,55846+0,0304944$ * ANO & $3,05 \%$ \\
\hline Musical & $4,93138-0,0816691{ }^{*}$ ANO & $(8,17 \%)$ \\
\hline Interpessoal & $4,52642+0,109323$ * ANO & $10,93 \%$ \\
\hline Intrapessoal & $4,36226-0,00678357$ * ANO & $(0,67 \%)$ \\
\hline Naturalista & $4,37033-0,244684$ * ANO & $(24,47 \%)$ \\
\hline
\end{tabular}

Fonte: Dados da pesquisa.

Com relação às 8 inteligências analisadas apenas três delas demonstram acréscimo na média ao longo dos 5 anos do curso de graduação em administração, são elas: inteligência lógico- matemática $(18,41 \%)$, a inteligência interpessoal com acréscimo de $(10,93 \%)$ e por fim a inteligência corporal cinestésica com (3,05\%) como podemos observar no quadro 2:

\begin{tabular}{|l|l|l|}
\hline Inteligência & Equação & Variação \\
\hline Lógico-matemática & $3,86262+0,184057$ * ANO & $18,41 \%$ \\
\hline Interpessoal & $4,52642+0,109323$ * ANO & $10,93 \%$ \\
\hline Corporal-cinestésica & $4,55846+0,0304944$ * ANO & $3,05 \%$ \\
\hline
\end{tabular}

Quadro 2 - Resultado da pesquisa Inteligências Múltiplas com Acréscimo

Fonte: Dados da pesquisa.

Sendo assim, já se permite fazer observações, ou seja, se faz necessário revisar algo sobre a forma como a didática empregada em sala de aula pode auxiliar no desenvolvimento geral das inteligências.

A inteligência lógico-matemática foi uma das duas inteligências com reconhecida significância ao lado da inteligência naturalista, embora esta última fique na condição negativa. A equação que expressa a variação da inteligência lógicomatemática é demonstrada a seguir.

Equação de regressão: LOG_MAT $=3,86262$ $+0,184057$ * ANO

Baseado na equação acima e no quadro 1 pode-se observar que a inteligência lógicomatemática inicie no patamar mais baixo entre todas as inteligências (38,63\%) apresenta o maior crescimento médio entre todas elas, tendo como média de $(18,41 \%)$ ao ano, um valor extremamente significativo, tão relevante que de forma linear poderia chegar muito próximo de dobrar o valor do ano 1 ao término do curso.

Diante do apurado nível de desenvolvimento desta inteligência ao longo do curso de Administração, percebe-se que muito embora os discentes cheguem ao curso com este ponto necessitando de desenvolvimento, todavia, a estrutura, a grade do curso, o corpo docente ou ainda a cultura do corpo discente traz consigo uma aptidão especial para esta inteligência. Gardner (2003) traz uma observação como os recursos de informática têm surgido nos últimos anos e está sendo vinculada a nossa cultura de tal modo que 
suas características de padrões racionais criam esferas do conhecimento concretamente como também é concebida a inteligência lógicomatemática; fato este comprovado no Brasil pelos estudos de Passarelli (1995) sobre utilização de multimídia na educação aliada a teoria das inteligências múltiplas.

Existem atividades didáticas que privilegiam indivíduos com a inteligência lógica desenvolvida ou propensa ao seu desenvolvimento como: jogos de empresas, estudo de caso, jogos numéricos, solução de problemas entre outros. No que se refere a estratégias para lidar com isso em sala de aula, pode-se colocar 4 itens de acordo com Armstrong (2001): quantificar uma coisa, ou seja, tentar buscar em casos e relatos de sala de aula uma forma de adequá-la em uma matriz de forma quantitativa. Pensar criticamente sobre ela, ao ser lançado um tema para discussão entre a turma, deve ser estimulado o pensamento crítico, imparcial e de cunho apurar a maior possibilidade possível de faces daquele fato, assim estimular-se-ia a lógica do indivíduo. A terceira estratégia, colocar os fatos em uma estrutura lógica, desta forma quando um problema é lançado para uma turma o docente tende a estimular para que todos tentem desmistificar o problema passo a passo colocandoo em plano onde possam observá-lo de um ponto de vista lógico. A última estratégia seria a experimentação, estimular o discente para que ele visualize na prática e entenda a relação estabelecida entre teoria e prática e o quão lógico isto pode ser.

No que se refere à inteligência interpessoal 0 desempenho mostrou-se significativo no ano 1 , sinaliza um nível de $(45,26 \%)$ do total possível, além de demonstrar um crescimento médio anual de $(10,93 \%)$, sendo uma das três inteligências a apresentarem características de avanço, a equação que comprova estas afirmações está expressa abaixo:

Equação de regressão: INTER = 4,52642 $+0,109323$ * ANO

O demonstrativo de crescimento da inteligência interpessoal traz consigo uma coerência com a formação propiciada ao curso de graduação em administração, como já exposto em outros momentos este estudo não impõe afirmações. Entretanto, pressupõe-se devido às disciplinas oferecidas (FURB, 2008) que as características desta inteligência são paralelas às desejadas para o futuro administrador, sendo o eficiente relacionamento com os outros e a percepção sobre aspectos pessoais de outros indivíduos uma das mais importantes no período contemporâneo.
Dentre as estratégias passíveis de melhoria no processo de estímulo do conhecimento, podem ser destacadas para públicos focados na inteligência interpessoal as seguintes: interação interpessoal; mediação de conflito; envolvimento na comunidade (extensão universitária); clubes, diretórios ou centros acadêmicos; participação em eventos, reuniões da categoria entre outras formas de aprimorar o relacionamento interpessoal e iniciar a formação de redes de contatos (ARMSTRONG, 2001).

Complementar a questão de estratégias didáticas para o aprimoramento da inteligência interpessoal pode-se acrescer os estudos de Passarelli (1995) que já utilizava experimentos de educação aliada a multimídia na metade da década passada, sendo que ponderava sob o seguinte aspecto: a agradabilidade criada pelo ambiente computacional para o estudante gerando uma interface entre sistema e usuário.

Nas questões referentes ao inventário utilizado na coleta de dados houve duas afirmações que receberam valores significativos, são elas:

"Tenho pelo menos três amigos íntimos (63,93\%)."

"Prefiro passar minhas noites em uma festa animada do que ficar em casa sozinho (62,95\%)."

Diante destas afirmações pode-se interpretar que estes discentes estão na busca de novas redes de contatos, sendo a inteligência interpessoal uma característica importante para êxito nesta busca.

A inteligência corporal-cinestésica apesar da "aparente" ausência de relação com o estudo da administração demonstrou um alto valor na percepção dos alunos, apontou um total de $(45,58 \%)$ do total possível no primeiro ano do curso de administração. Outro dado interessante remete ao fato desta inteligência ser uma das três inteligências que manifestaram acréscimo ao longo do curso de graduação com (3,05\%) ao ano. Estes dados são descritos na equação desta inteligência, colocada a seguir:

Equação de regressão: COR_CIN $=4,55846$ $+0,0304944$ * ANO

Como exposto no parágrafo anterior, "aparentemente" não haveria muita relação entre a inteligência corporal-cinestésica e o estudante de administração, mas duas perguntas do inventário de Armstrong (2001) ajudam na compreensão desta variação. Os discentes tinham 10 afirmações para assinalar referente a esta inteligência, duas delas foram assinaladas por quase $(60,00 \%)$ dos discentes, são elas: 
"Tenho dificuldades em permanecer quieto por longos períodos de tempo (60,33\%)."

"Freqüentemente gesticulo ou uso outras formas de linguagem corporal quando converso com as pessoas $(59,02 \%)$."

Considerando-se que o futuro administrador deverá reunir características de boa oratória e expressão fluente de suas idéias para todos os públicos, justificar-se-ia a participação intensa desta inteligência de forma média ao longo de todo o curso de graduação. Esta demonstração fica evidenciada na grade curricular por meio de disciplinas como Comunicação Empresarial Oral no $1^{\circ}$ ano, Processos de Negociação $3^{\circ}$ ano e oferece uma terceira disciplina optativa Desenvolvimento da Criatividade (FURB, 2008).

Podem ser expostas outras formas de melhoramento desta inteligência conforme Armstrong (2001) e aplicáveis a referida graduação, tais como: saídas de campo, o uso de imagens cinestésicas, programas de computador de realidade virtual, entre outras atividades. Verifica-se no quadro 3 as inteligências múltiplas que tiveram na média decréscimos ano a ano, durante o curso, foram às inteligências naturalista (24,47\%), inteligência musical $(8,17 \%)$, inteligência lingüística $(4,83 \%)$, inteligência espacial $(3,84 \%)$ e inteligência intrapessoal $(0,67 \%)$.

\begin{tabular}{|l|l|l|}
\hline Inteligência & Equação & Variação \\
\hline Naturalista & $4,37033-0,244684$ * ANO & $(24,47 \%)$ \\
\hline Musical & $4,93138-0,0816691$ * ANO & $(8,17 \%)$ \\
\hline Lingüística & $4,13784-0,0482585$ * ANO & $(4,83 \%)$ \\
\hline Espacial & $3,98054-0,0384001$ * ANO & $(3,84 \%)$ \\
\hline Intrapessoal & $4,36226-0,00678357$ * ANO & $(0,67 \%)$ \\
\hline
\end{tabular}

Quadro 3 - Resultado da pesquisa Inteligências Múltiplas com decréscimo.

Fonte: Dados da pesquisa.

Com relação às inteligências múltiplas que apresentaram decréscimos observa-se a inteligência naturalista, esta inteligência foi ao lado da inteligência lógico-matemática a única a demonstrar significância no método de análise de regressão e correlação utilizadas nesta pesquisa. Entretanto, diferencia-se da outra inteligência no ponto inicial com um valor relevante $(43,70 \%)$ e também por apresentar uma variação negativa na casa de $(24,47 \%)$ ao ano, a representação estatística destas afirmações pode ser expressa pela equação a seguir:

Equação de regressão: NATU = 4,37033 0,244684 * ANO

A representação desta inteligência traz uma constatação preocupante, em média, esta inteligência terá sido quase anulada antes do término do curso, afinal com um recuo de quase $(25,00 \%)$ ao ano, ou seja, $1 / 4$ do valor total apresentado no ano 1.

Não se pode adentrar no mérito para justificar a queda brusca da referida inteligência, afinal estaria baseada em pressupostos e demonstrações cognitivas. Então, este artigo limita-se a fornecer estratégias didáticas que podem ser utilizadas pelos docentes para evitar o recuo, manter o status ou até mesmo buscar um avanço na inteligência naturalista.
Não existem muitas alternativas para relacionar a inteligência naturalista com o ensino da administração, mas devem-se respeitar aqueles que possuem uma maior concentração nesta inteligência, desta forma cabe um preparo das aulas de modo facilitar o aprendizado destes indivíduos.

Armstrong (2001) coloca alguns pontos que podem ser trabalhados para reforçar a inteligência naturalista, podem-se destacar estes: caminhadas ao ar livre, vídeos e filmes sobre a natureza, ecoestudo. Acrescentar-se-ia que devido a recente preocupação evidenciada na mídia por questões ambientais, em especial o aquecimento global (SAMPAIO, 2008). Estes acadêmicos que serão futuros administradores podem começar a utilizar tal inteligência na busca de uma administração que não comprometa as gerações futuras, dotados de uma gestão mais responsável, apenas para citar uma das formas de abranger o uso desta inteligência no curso de graduação em administração.

Cabe ressaltar que apenas uma das afirmações expostas para avaliar a inteligência naturalista demonstrou relevante significância, conforme se pode verificar na frase a seguir:

"Prefiro passar minhas férias em ambientes naturais como uma praia ou camping com trilhas 
ecológicas do que em locais urbanos ou culturais como um hotel dentro de uma cidade (60,33\%)"

Esta expressão é interpretada de forma isolada, afinal as demais afirmações não apresentaram níveis consideráveis, logo, pode-se interpretar que tal preferência em buscar lugares isolados em períodos de repouso deve-se mais a procura por um repouso do cotidiano e da pressão impostas pela sociedade contemporânea do que por uma afinidade naturalista.

A inteligência musical foi à inteligência que apresentou o maior nível entre todas as inteligências analisadas, no primeiro ano, ponto inicial da pesquisa, mostrava-se com $(49,31 \%)$ do total possível, sintetizando, estes alunos demonstram uma tendência musical muito grande no início do curso, interpreta-se também que esta musicalidade decai fortemente ao longo dos anos de graduação.

Em contrapartida, sinaliza a segunda maior queda de todas as inteligências, sinaliza um recuo médio anual na ordem de $(8,17 \%)$ ao ano, valor este expresso pela equação abaixo:

Equação de regressão: MUS $=4,93138$ 0,0816691 * ANO

Partindo desta premissa, analisam-se duas importantes considerações, a musicalidade está muito forte nos primeiros anos de curso, logo, cabe utilizar-se de mecanismos didáticos musicais para atingir uma comunicação eficaz com todos os discentes. Outra importante consideração e que, não pôde ser medida por esta pesquisa é, o motivo pela queda tão brusca de um ponto tão evidente, ou seja, como uma inteligência que fica tão acima das outras no início pode ser ter uma média decrescente tão alta.

Existem pressupostos cognitivos que podem sugerir alguns motivos como: ausência de atividades iniciais voltadas à musicalidade e foco central em atividades técnicas da profissão ao longo do curso que acabam por não privilegiar estratégias de manutenção para a referida inteligência.

Podem-se utilizar estratégias didáticas (Armstrong, 2001) que mantenham esta inteligência de forma equilibrada ao longo dos cinco anos da graduação, tais como: usar músicas de fundo (no início das aulas como forma de harmonizar o ambiente); vincular melodias antigas a conceitos; observar as imagens com temas musicais e executar programas de computador com música.
A inteligência lingüística pode ser expressa a sua participação ao longo dos cinco anos da seguinte forma:

Equação de regressão: LING $=4,13784$ 0,0482585 * ANO

Assim, a equação demonstra que ao longo dos anos, a inteligência lingüística apresenta um decréscimo de (4,83\%) ao ano, é um valor relativamente significante, pois ao término de 5 anos o aluno terá reduzida esta inteligência em mais de $1 / 5$ do valor inicial. Como apresentado nos parágrafos anteriores esta inteligência é uma das três que demonstraram uma redução na média ao longo dos 5 anos de curso, embora apresente um valor importante no ponto inicial da pesquisa $(41,38 \%)$, não dispensa a necessidade de busca em técnicas e mecanismos de ensino para manter a percepção por parte dos discentes para a mesma.

Na pesquisa desenvolvida para este artigo não se buscou as possíveis causas para a queda na percepção desta inteligência por parte dos discentes. Contudo, pode-se pressupor uma série de possíveis causas, dentre elas a ausência de atividades por parte dos docentes visando privilegiar os alunos que possuem afinidade com esta inteligência ou mesmo para manter desenvolvida esta inteligência como se apresentou no primeiro ano.

Observa-se uma percepção acentuada nesta inteligência por meio de uma das afirmações do inventário, constando da seguinte forma:

"Meus diálogos incluem freqüentemente referências a coisas que li ou ouvi $(65,90 \%)$ "

Baseado nesta afirmação, as leituras dos acadêmicos ou a rede de contatos dos mesmos fornecem muitos subsídios para argumentações futuras, sendo assim uma das formas como é percebida a inteligência lingüística por parte dos discentes.

Armstrong (2001) coloca cinco estratégias de ensino que podem ser utilizadas didaticamente e que podem contribuir para a evolução da inteligência lingüística, são elas: narração de histórias; explosão de idéias; gravação em fita cassete; redação de um diário e publicações.

A estratégia de narração de histórias normalmente não se aplicaria em ambientes universitários, mas as estratégias restantes podem perfeitamente conduzir atividades que estimulem o aprendizado pela aptidão lingüística. A explosão de idéias, ou braistorming pode ser utilizada como 
mecanismo de criação ou recuperação de conteúdos por meio da participação dos alunos.

A gravação em fita cassete ou digital pode ser usada como forma de coleta de dados ou ajudando os alunos a refletir sobre posturas utilizadas em sala de aula. Já a redação de um diário embora seja de difícil conciliação com as atividades normais dos planos de ensino, colabora e muito no sentido de mostrar ao discente o prazer da escrita e como ele pode reconhecer-se por meio da mesma (desta forma também se estimula à inteligência intrapessoal), além de permitir relembrar acontecimentos diários. Armstrong (2001) ainda complementa que as apresentações expositivas têm sido excessivamente exageradas e por isso não a inclui nestas estratégias.

Na realidade não se necessita ir a extremos de abolirem-se as aulas expositivas, pois elas são eficazes dependendo da relação rigorosamente de qualidade entre professor e aluno, sendo ainda um mecanismo válido para transmissão deste tipo de conhecimento. (LOWMAN, 2004)

A inteligência espacial foi ao lado da inteligência lógico-matemática a única que no ano 1 não atingiu $(40,00 \%)$ do total possível na percepção dos discentes, todavia, ao contrário desta outra inteligência, a inteligência espacial demonstra um decréscimo médio ao longo do curso no valor de $(3,84 \%)$ ao ano, um valor significante. Porém que pode ser associado com foco do curso em outras inteligências consideradas mais próximas da profissão de administrador. Pode-se descrever matematicamente a equação que representa este decréscimo da seguinte forma:

Equação de regressão: ESPA = 3,98054 0,0384001 * ANO

Muito embora a quantificação da inteligência espacial tenha sido baixa, aqueles indivíduos que a tenham como altamente desenvolvida devem ser atendidos em sala de aula satisfatoriamente, exemplificando, cabe ao docente colocar os conteúdos de maneira a aperfeiçoar a transmissão da mensagem.

Ocorre que uma série de técnicas pode e deve ser utilizada em sala de aula para facilitar a aprendizagem de alunos propensos à inteligência espacial, entre estas se podem colocar: software gráfico de computador, gráficos, diagramas, mapas, vídeos, slides, filmes entre outras (ARMSTRONG, 2001).

Atualmente a FURB dispõe de grande parte das salas de aula com projetores multimídia e pontos de conexão a internet, diante deste cenário fica nítido a possibilidade de utilização por parte da docência de uma variedade de itens propostos por Armstrong, além de acrescentar ao portfólio de técnicas o Ambiente Virtual de Aprendizagem (AVA) que oferecem uma excelente diversidade de recursos (DALFOVO, 2007). Instrumento este, que permite adicionar uma variedade de técnicas e ainda possibilitar interação do docente versus discente para o aprimoramento de todas as inteligências, neste caso a espacial.

E por fim analisando os resultados da inteligência intrapessoal que parte no ano 1 de $(43,62 \%)$ e apresenta uma evolução ao longo dos anos quase nula, reduzindo $(0,67 \%)$ em média ao ano, ou seja, permanece quase estática no período analisado. Estes dados podem ser expressos conforme a equação abaixo.

Equação de regressão: INTRA = 4,36226 0,00678357 * ANO

$\mathrm{Na}$ análise desta inteligência, três afirmações tiveram enorme significância para os respondentes desta pesquisa, são estas descritas a seguir:

"Sou capaz de reagir as dificuldades com coragem (63,28\%)."

"Tenho alguns objetivos importantes na minha vida sobre os quais reflito regularmente (77,38\%)."

"Eu me considero uma pessoa determinada, com idéias próprias $(65,57)$."

Baseado na análise destas três afirmações pode-se confirmar um dos objetivos determinados para o curso de graduação e exposto na página virtual do curso: "Um dos seus principais objetivos é formar administradores com capacidade empreendedora [...]" (FURB, 2008).

A capacidade empreendedora com certeza traz consigo algumas das afirmações expostas em grande quantidade pelos discentes, a objetividade na vida ou carreira profissional e o monitoramento constante destes objetivos. Outra característica importante evidencia-se pelo determinismo e capacidade de gerar novas idéias, ambas, importantes caminhos para o êxito empreendedor na carreira profissional do administrador.

Outro fator preponderante na análise da inteligência é a capacidade de autodisciplina, Lowman (2004) coloca que uma parcela importante do processo de aprendizagem é a busca pelo conhecimento, independente do curso, a realização sozinho de tarefas ou ainda atividades que necessitem de autodisciplina transcendem para um nível de conhecimento muito importante, integrando 
o aprendizado da sala de aula com vivencias do próprio discente.

No caso do curso de graduação em administração da FURB isto se evidencia pela utilização de ferramentas no AVA ou ainda de utilização de disciplinas semi-presenciais, sendo assim a inteligência intrapessoal extremamente relevante para o sucesso do indivíduo ao término da disciplina ou mesmo do curso.

Também nesta inteligência Armstrong (2001) demonstra algumas estratégias de ensino que podem ser utilizadas para complementar a inteligência ou mesmo aprimora-la, podem-se destacar algumas como: espaços privados para estudo, atividades de estudo com opções para tema de casa, atividades de auto-estima e ainda a manutenção de um diário (já citada na inteligência lingüística).

O curso de graduação em administração oferece ainda no primeiro ano três disciplinas que ajudam na manutenção do status desta inteligência, são elas: Ética e Filosofia, Sociologia e Psicologia Organizacional. Estas três cadeiras trazem na sua ementa discussões que privilegiam a busca pela melhor identificação do indivíduo.

\section{Conclusões e Recomendações}

As inteligências múltiplas são faculdades independentes do ser humano, sua formação origina-se de sua interação com o ambiente que o cerca, influenciando sua forma de pensar e agir.

A teoria das inteligências múltiplas foi desenvolvida como uma teorização da cognição humana que pode ser avaliada por meio de testes empíricos, onde seus resultados podem sugerir informações pedagógicas relevantes que merecem ser consideradas.

O estado ideal de conhecimento do discente deveria representar um equilíbrio entre as inteligências (GARDNER, 1994; ARMSTRONG, 2001). O que se pode verificar ao se desenvolver conteúdos de acordo com necessidades das inteligências mais notórias e desenvolvidas entre os discentes, se levará a uma maior assertividade no canal de comunicação. Considera-se ainda que inteligências com pouca representatividade devam ser estimuladas e aperfeiçoadas através de atividades e métodos de ensinos complementares.

Os resultados da pesquisa demonstram evoluções, evidenciando acréscimos e decréscimos entre as inteligências do início da graduação até o término do curso. Cabe ressaltar que não se identificou diferenças entre gêneros de forma significativa e assim não merecendo uma maior atenção neste estudo.

O estudo feito enfatiza a importância e a aplicabilidade dos estudos de Gardner (1994) e de Armstrong (2001) ao ensino superior, pois por meio das análises foi possível sugerir propostas e atividades aos docentes e a instituição com objetivo de melhor equilibrar e desenvolver as múltiplas inteligências entre os discentes para promover 0 ensino com diferentes metodologias de acordo com as necessidades e potencialidades dos discentes.

Observou-se entre os discentes pesquisados que a inteligência com maior crescimento foi à inteligência lógico- matemática, demonstrando o interesse dos discentes pelas atividades relacionadas ao raciocínio lógico e quantitativo, também relacionada à natureza da ciência administração, ela parte do ano 1 com o menor índice entre todas as inteligências $(38,63 \%)$ e apresenta o maior crescimento médio entre todas elas, tendo como média de crescimento $(18,41 \%)$ ao ano, um valor extremamente significativo, tão relevante que de forma linear poderia chegar muito próximo de dobrar o valor do ano 1 ao término do curso. Este ótimo desempenho deva-se talvez a excelente matriz curricular e a condução das disciplinas correspondentes da inteligência lógicomatemática.

Outra inteligência que se destacou notoriamente foi à inteligência interpessoal que parte do ano 1 com um índice de $(45,26 \%)$ do total possível e demonstra um crescimento médio de $(10,93 \%)$ ao ano até o final do período. Esse destaque provavelmente deve-se a afinidade com a área das ciências sociais, em específico a administração, onde pessoas necessitam ter e ou deveriam desenvolver interação com outras pessoas em sua vida profissional ou acadêmica. Este destaque pode ser resultado da metodologia aplicada em sala de aula e do interesse dos discentes aos temas relacionados.

A inteligência corporal-sinestésica apesar da "aparente" ausência de relação com o estudo da administração demonstrou um alto valor na percepção dos alunos, apontou um total de $(45,58 \%)$ do total possível no primeiro ano do curso de administração, e demonstrou um crescimento médio de (3,05\%) ao ano durante o curso. Pressupõe-se que devido ao fato da necessidade de boa comunicação do administrador frente a diversas situações que envolvam pessoas, estas características são estimuladas e descobertas entre os discentes durante o curso, por meio de estratégias e didáticas apropriadas durante as 
disciplinas correspondentes a esta inteligência em particular.

A inteligência que obteve variação menos significante foi à inteligência intrapessoal, demonstrou inicialmente um alto valor na percepção dos alunos, ou seja, apresentou um índice de $(45,58 \%)$ do total possível no primeiro ano do curso de administração. Demonstrou um decréscimo médio de $(0,67 \%)$ ao ano durante o curso, apresentando que esta inteligência esta sendo desenvolvida de forma mediana, com resultados apenas mantedores da mesma. Sugerese o maior envolvimento do corpo docente nas atividades de estímulo e desenvolvimento desta inteligência em sala de aula, pois envolve determinação e ações para o alcance de suas realizações, sejam profissionais ou pessoais dos discentes.

Pode-se verificar também que as inteligências natural, musical e lingüística, tiveram uma acentuada queda no decorrer dos anos, isso provavelmente justifica-se por meio da falta de estímulo e da não utilização dos meios estratégicos ao seu desenvolvimento entre os discentes.

Vale ressaltar, ainda, que todos os discentes em todos os anos apresentaram índices consideráveis em todas as inteligências, corroborando com Gardner (1994), que afirma que todas as pessoas possuem oito inteligências e estas funcionam juntas e de maneira complexa.

Conclui-se que metodologia de ensino e a correta adequação de conteúdos e da grade curricular causam impacto no processo da aprendizagem e no desenvolvimento das inteligências múltiplas entre os discentes. Através desses resultados, sugere-se a direção de ensino, coordenação e ao corpo docente do curso promovam as inteligências que foram desenvolvidas e apresentaram acréscimo e desenvolvam as inteligências com decréscimo e deficitárias, necessárias ao bom desempenho do profissional de administração.

\section{Referências}

ANTUNES, C. As inteligências múltiplas e seus estímulos. 4. ed. Campinas: Papirus, 1998.

O que mais perguntam sobre as inteligências múltiplas. Florianópolis: CEITEC, 2003.

ARMSTRONG, T. Inteligências múltiplas na sala de aula. 2. ed. Porto Alegre: Artmed, 2001.
DALFOVO, M. S. O estudo do uso dos recursos do ambiente virtual de aprendizagem (AVA) no Curso de Graduação de Administração da Universidade Regional de Blumenau. 2007.136 f, il. Dissertação (Mestrado em Administração) - Programa de PósGraduação em Administração, Centro de Ciências Sociais Aplicadas, Universidade Regional de Blumenau, Blumenau, 2007.

FLECK, C. F. Inteligências múltiplas e comportamento gerencial: estudo da relação entre os perfis dos coordenadores de pós- graduação das universidades federais do RS. Santa Maria: UFSM, 2008. 159 p. Dissertação - Programa de Pós-Graduação em Administração, Universidade Federal de Santa Maria, Santa Maria, 2008.

GARDNER, H. Estruturas da mente: a teoria das inteligências múltiplas. Porto Alegre: Artes Medicas, 1994.

Multiple intelligences after twenty years. Chicago, Illinois: American Educational Research Association. Disponível em: <http://www.vusst.hr/ berislav/phed/HG_Ml_after_2 0_years.pdf > Acesso em: 29 mai. 2008.

HAIR, J. F. et al. Análise multivariada de dados. 5. ed. Porto Alegre : Bookman, 2005.

KONG, Y. A study on multiple intelligences theory and English language teaching. International Education Studies. v., n. 1, p. 133-138, 2009.

LOWMAN, J. Dominando as técnicas de ensino. São Paulo: Atlas, 2004.

MOKHTAR, I. A.; MAJID, S.; FOO, S. Information literacy education through mediated learning and multiple intelligences. Reference Services Review. v. 35, n. 3, p. 463-486, 2007.

MORAN, S.; KORNHABER, M.; GARDNER, H. Orchestrating multiple intelligences. Educational Leadership, v. 64, p. 22-27, 2006.

NIELSEN, Tine. Implementation of learning styles at the teacher level, Education + Training. v. 50, n. 2, p. 155-166, 2008.

PASSARELLI, B. A teoria das inteligências múltiplas aliada à multimídia na educação: novos rumos para o conhecimento. In: III Simpósio Brasileiro de Geoprocessamento, 1995, São Paulo. Anais do III Simpósio Brasileiro de Geoprocessamento. São Paulo: Escola Politécnica da Universidade de São Paulo, 1995. v. 1. p. 151170.

SAMPAIO, C. A. C.; MANTOVANELI JR, O. Para pensar uma nova racionalidade de tomada de decisão que promova o desenvolvimento sustentável. RAE. Revista de Administração de Empresas, 2008. 


\section{Universidade Regional de Blumenau (FURB). Blumenau, 2008. \\ Disponível \\ em}

<http://www.furb.br/2005/arquivos/620493-

787429/Administracao\%20Gestao\%20Empresarial \%20\%20Noturno\%202003\%201.PDF > Acesso em 05. jul. 2008.

WALTER, S. A.; FLORES, D. C.; DOMINGUES, M. J. C. de S.; LAUER, F.; SCHNEIDER, M. A. Ensinando e aprendendo a partir das inteligências múltiplas: estudo no curso de administração da PUCPR, Campus Toledo, Paraná, Brasil. In:
SILVEIRA, A.; DOMINGUES, M. J. C. de S.. (Org.). Ensino na área de administração e avaliação em Instituições de Ensino Superior. Blumenau: EDIFURB, 2006, v. 1, p. 109-130.

Similaridades e divergências no desenvolvimento das inteligências múltiplas de um curso de Ciências Contábeis: um comparativo entre cursos, turmas e gêneros. In: Congresso USP de Controladoria e Contabilidade, 8. São Paulo, 2008. Anais... São Paulo: Congresso USP de Controladoria e Contabilidade, 2008.

PESQUISA SOBRE INTELIGÊNCIAS MÚLTIPLAS (IM)

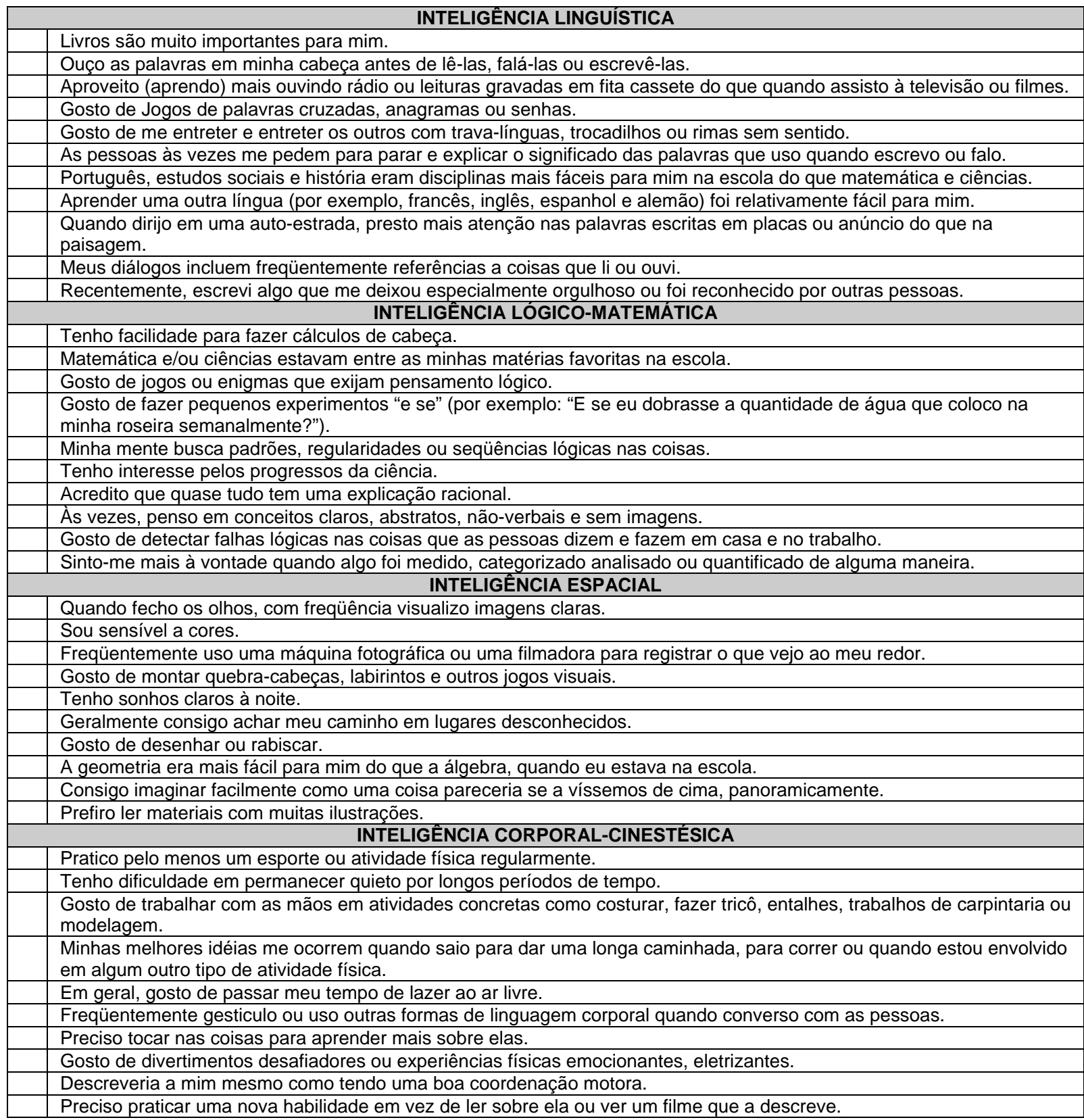




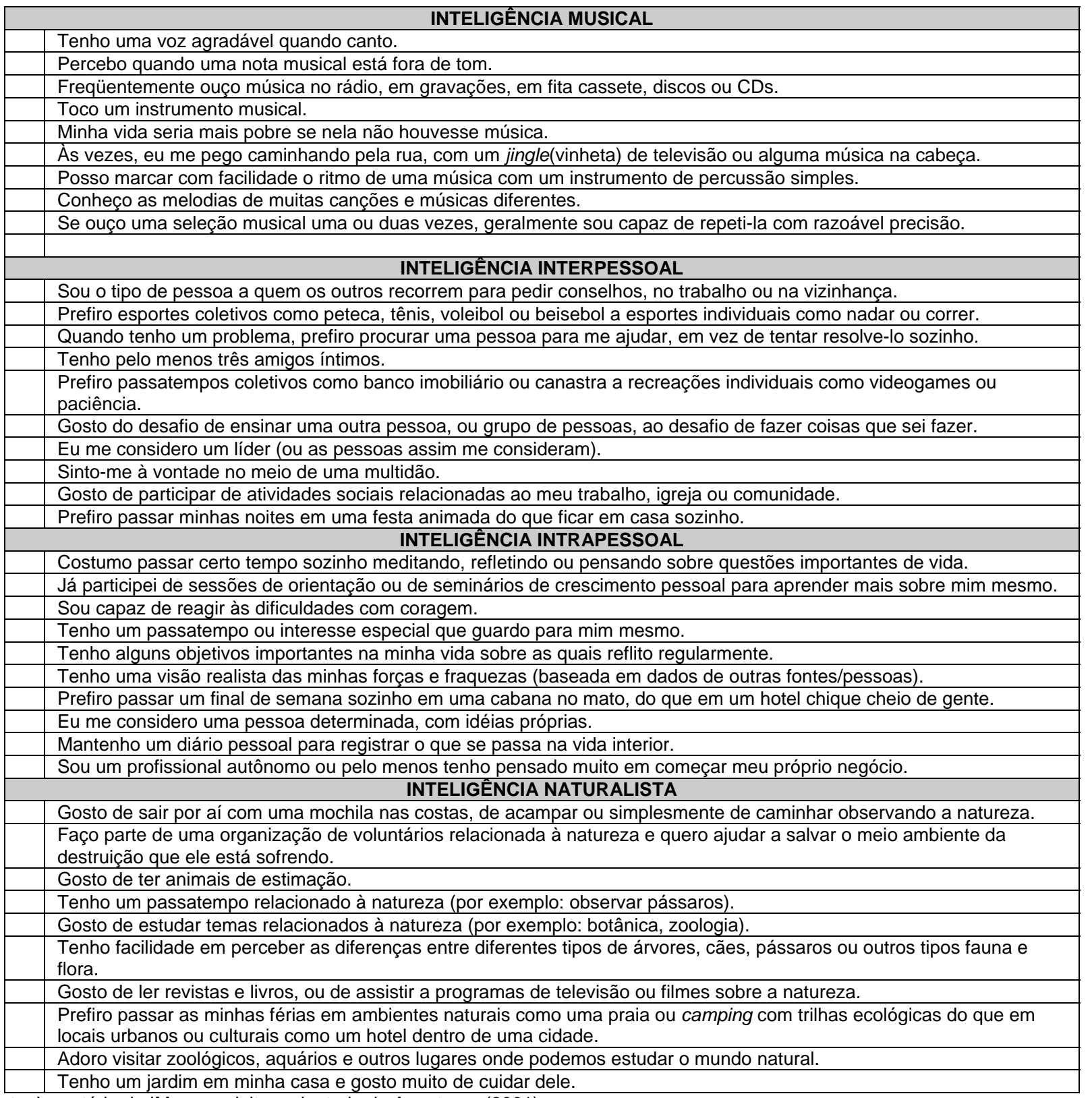

Fonte: Inventário de IM para adultos adaptado de Armstrong (2001). 